\title{
An Unusual Cause of Dysphagia
}

CARLO PALAZZI, MD, Senior Investigator, Rheumatology Department of Lucania, San Carlo Hospital of Potenza and Madonna delle Grazie of Matera; SALVATORE D'ANGELO, MD, Researcher, Rheumatology Department of Lucania, San Carlo Hospital of Potenza and Madonna delle Grazie of Matera; PhD Scholarship in Health Sciences, Department of Health Sciences, University of Molise, Campobasso; IGNAZIO OLIVIERI, MD, Consultant, Director, Rheumatology Department of Lucania, San Carlo Hospital of Potenza and Madonna delle Grazie of Matera, Matera, Italy. Address correspondence to Dr. C. Palazzi, Via Potenza 3, 75100 Matera, Italy. E-mail: kaps57@virgilio.it. J Rheumatol 2011;39:184; doi:10.3899/jrheum.110917

Diffuse idiopathic skeletal hyperostosis (DISH) is a well-recognized cause of dysphagia ${ }^{1}$; we describe a case of an esophageal compression by a DISH cervical osteophyte.

A 62-year-old man came to our rheumatology clinic with an 8-year history of progressive spinal stiffness and a 4-year history of worsening dysphagia for solid foods. At admission, he showed a conspicuous limitation of spinal mobility, with neck motion substantially suppressed. A reduced chest expansion was evident. Shoulders and hips were also slightly limited. Thus he showed the typical postural abnormalities of ankylosing spondylitis (AS). The severe dysphagia allowed him to swallow only liquids.

Radiographs of the cervical, dorsal, and lumbar spine showed bony proliferations typical of DISH. In particular, the lateral view of the cervical spine revealed bulky "flowing mantles" of ossification in the anterior longitudinal ligament extending from the second to the seventh vertebra (Figure

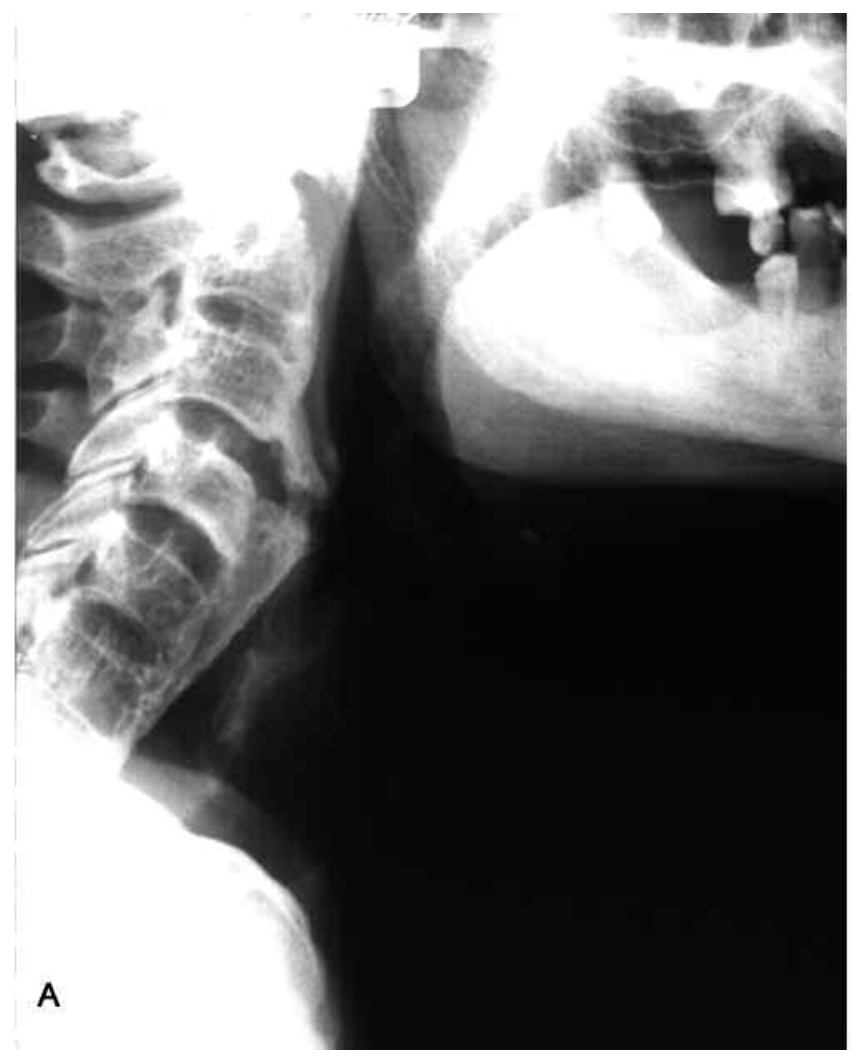

$1 \mathrm{~A})^{2}$. The DISH had clinically mimed AS, as we have previously described ${ }^{3}$. A barium swallow procedure confirmed the external pressure on the esophagus by a "monstrous" bony proliferation, with only a threadlike lumen remaining (Figure 1B).

DISH is a well-recognized cause of dysphagia ${ }^{1}$, but we had never observed a similarly impressive esophageal compression.

\section{REFERENCES}

1. Mader R. Clinical manifestations of diffuse idiopathic skeletal hyperostosis of the cervical spine. Semin Arthritis Rheum 2002;32:130-5.

2. Olivieri I, D’Angelo S, Palazzi C, Padula A, Mader R, Khan MA. Diffuse idiopathic skeletal hyperostosis: differentiation from ankylosing spondylitis. Curr Rheumatol Rep 2009;11:321-8.

3. Olivieri I, D'Angelo S, Cutro MS, Padula A, Peruz G, Montaruli M, et al. Diffuse idiopathic skeletal hyperostosis may give the typical postural abnormalities of advanced ankylosing spondylitis. Rheumatology 2007;46:1709-11.

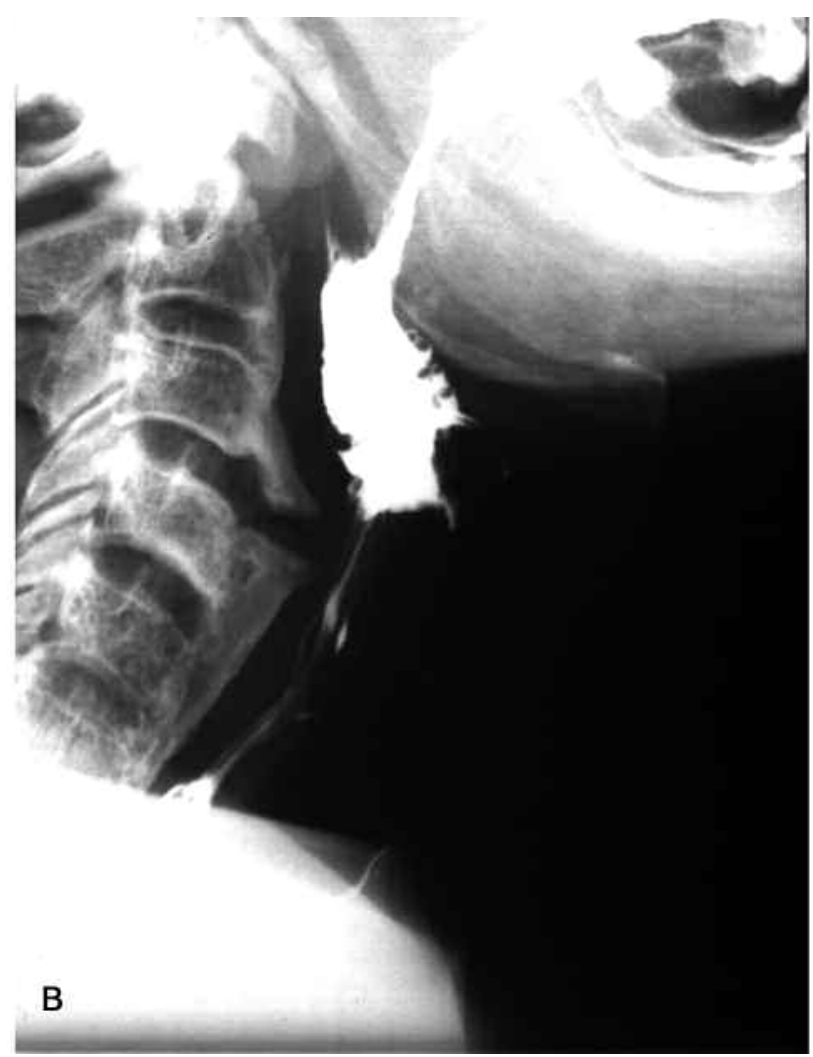

Figure 1. A. Lateral radiograph of the cervical spine revealed bulky "flowing mantles" of ossification in the anterior longitudinal ligament extending from the second to the seventh vertebra. B. A barium swallow procedure confirmed external pressure on the esophagus by a bony proliferation, with only a threadlike lumen remaining.

Personal non-commercial use only. The Journal of Rheumatology Copyright (C) 2012. All rights reserved. 